\title{
O LUGAR DE PAULO FREIRE NA FORMAÇÃO E NOS SABERES DOS PROFESSORES
}

\section{PAULO FREIRE'S PLACE IN EDUCATION AND KNOWLEDGE OF TEACHER}

\section{Resumo}

Tatiana Pinheiro de Assis Pontes ${ }^{1}$ Cristiano Amaral Garboggini Di Giorgi ${ }^{2}$

Este estudo partiu da problemática concernente ao lugar ocupado por Paulo Freire nos referenciais teóricos de professores de educação básica de escolas públicas brasileiras. Consideramos os estudos sobre Paulo Freire de suma importância nos processos formativos dos professores, sobretudo, para a construção da identidade profissional e para a formação de educadores progressistas, em favor da construção de uma escola democrática. Este estudo se curvou ao objetivo central de analisar o que os professores da atualidade sabem sobre o referido autor, reconhecendo a formação docente como espaço fundamental para a produção do referencial teórico e para a construção dos saberes docentes. A pesquisa empírica foi realizada em um município do interior paulista e contou com a participação de vinte professores atuantes em escolas públicas, municipais e estaduais, de educação básica, nos seguintes segmentos de ensino: Educação Infantil, Ensino Fundamental e Ensino Médio. A metodologia da pesquisa pautou-se na abordagem qualitativa, em face das possibilidades de desenvolvimento de ações fundamentadas na reflexão e no diálogo, sob as perspectivas freireanas. Os dados empíricos foram coletados por meio de questionário, com questões abertas e fechadas, e mediante realização de entrevistas individuais semiestruturadas. Concluiu-se que há lacunas no âmbito da Gestão educacional e das Políticas Educacionais para a formação de professores, tanto na esfera inicial como na formação continuada. Defende-se que, para Paulo Freire ocupar o lugar/espaço de referência teórica e repercutir na construção dos saberes docentes é fundamental a implementação de políticas e de ações específicas no âmbito da formação de professores.

Palavras-chave: Paulo Freire; Formação de Professores; Saberes docentes; Educação Críticolibertadora.

\begin{abstract}
This study started from the problem related to the place occupied by Paulo Freire in the theoretical references of basic education teachers from Brazilian public schools. We consider studies about Paulo Freire to be important in formative processes of teachers, mainly for the construction of professional identity and for the formation of progressive educators in favor of construction a democratic school. This study focused on the central objective of analyzing what today's teachers know about the mentioned author, recognizing teacher education as a

\footnotetext{
${ }^{1}$ Doutora em Educação pela UNESP. Professora Ajunta do Departamento de Educação - DECED - da UFSJ.

E-mail: tatianapinheiro@ufsj.edu.br

${ }^{2}$ Doutor pela USP. Professor Titular aposentado da UNESP. Atualmente Professor da UNOESTE. E-mail: utopico92@gmail.com
}

Revista Devir Educação, Lavras, vol.4, n.1, p.116-138 jan./jun., 2020. 
fundamental space for the production of theoretical reference and for the construction of teaching knowledge. Empirical research was held in a city in the interior of São Paulo, Brazil and was attended by twenty teachers working in public, municipal and state schools, of basic education, in following topics: Early Childhood Education, Elementary Education and High School. The research methodology presented a qualitative approach, in view of the possibilities of development of actions based on reflection and dialogue, from the perspective of Freire. Empirical data were collected through a questionnaire, with open and closed questions, and conducting individual semi-structured interviews. It was concluded that there are gaps in the fields of Educational Management and Educational Policies for teacher training, both in the initial sphere and in continuing education. We argue that for Paulo Freire occupy the place/space of theoretical reference and reverberate in the construction of teacher's knowledge, it is fundamental the implementation of policies and actions within the scope of teacher education.

Key words: Paulo Freire; Teacher education; Teacher knowledge; Critical-liberating education.

\section{Introdução}

A questão que este artigo procura responder se refere ao lugar ocupado por Paulo Freire nos saberes dos professores atuantes em escolas públicas de educação básica no contexto atual brasileiro.

A Educação é um campo de estudos e de políticas muito suscetível a novidades, a modismos que vêm e que vão, mas a obra de Paulo Freire é um clássico, pois não tem perda de irrigação de sua atualidade, apesar do tempo transcorrido. "Clássico é aquilo que não deixou de ter atualidade. É interessante porque a palavra 'atual' não significa apenas moderno, ela também significa, vindo do latim para o inglês, verdadeiro" (Cortella, 2011, p. 11).

Sobre isso, Cortella (2011) explana: O pensamento de Paulo Freire é novo, a música de Mozart é nova, a obra de Platão é
nova, Catulo da Paixão Cearense é novo. Por quê? Porque o seu trabalho não perdeu
vitalidade, não perdeu a irrigação, não perdeu a conexão com a vida e com o sangue
que a vida partilha e emana. Desse ponto de vista, o pensamento de Paulo Freire é
absolutamente atual, no sentido de guardar a sua forma de ser novo. Ele não é
novidade. A novidade é passageira, é fluida, ela escorre. Ele permanece (Cortella,
2011, p. 11).

Partindo dessa compreensão, concebemos a obra de Paulo Freire como fonte de saber fundamental para a (re) construção da escola pública fundada nos princípios da democracia. Essa escola, aqui chamada de crítico-libertadora, busca o desenvolvimento da conscientização 
de sua comunidade escolar diante do seu contexto cultural e social. A conscientização é um processo educacional que possibilita muito mais que o conhecimento sobre a realidade, pois promove a capacidade de decisão sobre que posturas homens e mulheres podem e devem assumir diante do mundo (FREIRE, 2003).

Considerando o fato de ser um fenômeno educacional, destacamos o papel político ocupado pelos professores no desenvolvimento da conscientização dos alunos e da comunidade escolar. Os docentes refletem suas posições, influenciando opiniões/concepções, tanto no desenvolvimento direto de suas atribuições junto aos alunos como por meio de sua conduta civil, em situações do cotidiano fora da escola. Cabe lembrar que tal concepção está em plena consonância com a Constituiçao Federal de 1988, que em seu Artigo 205, explicita que "A educação, direito de todos e dever do Estado e da família, será promovida e incentivada com a colaboração da sociedade, visando ao pleno desenvolvimento da pessoa, seu preparo para o exercício da cidadania e sua qualificação para o trabalho".

Partindo disso, vale lembrar um fato que motivou o desenvolvimento desta pesquisa. Trata-se do ocorrido no Brasil durante as manifestações populares realizadas no início de 2015 quando parte da população apoiava o processo que culminou no impeachment da então presidente da República Dilma Roussef (PT). Ocorre que, no dia 15 de março de 2015, em meio aos protestos contra o referido governo, em que os manifestantes pediam por impeachment e por intervenção militar, além dos xingamentos e de outras formas questionáveis de manifestação, uma faixa chamou bastante a atenção, não só no Brasil, mas em diversas partes do mundo, por expor a seguinte declaração: "Chega de doutrinação marxista. Basta de Paulo Freire". ${ }^{3}$

Entre tantos questionamentos e reflexões cabíveis ao episódio exposto, destacamos o fato de que a declaração partiu de um professor, da disciplina de História, que, entre outras coisas, pedia por intervenção militar no Brasil. Entre outras hipóteses, podemos supor que há o controle sobre o que os professores e a comunidade escolar devem saber e que isso vislumbra as perspectivas do momento, do modismo, da novidade, o que pode contribuir para o alheamento aos conhecimentos da teoria e da prática de Paulo Freire.

Outro fato que fortalece a hipótese de alheamento à obra e à práxis freireana, não só no campo educacional, mas na sociedade brasileira, consiste na recente tentativa parlamentar de

\footnotetext{
${ }^{3}$ A referida mensagem foi levada às ruas de Brasília pelo professor de história Eduardo Sallenave, de 27 anos. (STREIT, 2015).
} 


\section{Q0 DEVIR EDUCAÇÃO \\ ISSN: 2526-849X}

retirar o título de patrono da educação brasileira, conferido a Freire por meio da lei $\mathrm{n}^{\mathrm{o}} 12.612$. Ocorre que foi enviada ao congresso, pelos seguidores do movimento "Escola Sem Partido", uma proposta de revogação da lei $\mathrm{n}^{\circ}$ 12.612, que retiraria definitivamente o título conferido a Paulo Freire. A justificativa da proposta foi pautada na afirmação de que o educador é considerado um filósofo de esquerda e que os resultados do seu método de educação são um fracasso (Craide, 2018).

Observamos que o título que poderia significar o reconhecimento e a legitimação da importância do educador/autor para a história e para a realidade educacional brasileira contribuiu para revelar a manutenção de setores conservadores tão reacionários como a época da ditadura de 1964, em que Paulo Freire foi preso por tentar propagar a experiência exitosa de seu método de alfabetização, que se pautava na conscientização das pessoas quanto ao seu contexto histórico, cultural, político e social.

Felizmente, no dia 14 de dezembro de 2017, a Comissão dos Direitos Humanos e Legislação Participativa do Senado rejeitou a proposta de revogação da lei $\mathrm{n}^{\circ}$ 12.612, classificando-a como uma clara tentativa de censura ideológica ${ }^{4}$.

Sobre isso, a relatora, senadora Fátima Bezerra (PT-RN), se posicionou dizendo que seria um crime lesa-pátria retirar o título de patrono da educação brasileira de Paulo Freire, principalmente nesse momento de crise e de desesperança que o país atravessa, quando, na verdade, o legado freireano precisa ser resgatado (Craide, 2017).

Tal ação repercutiu internacionalmente, tanto que, no dia 20 de fevereiro de 2018 a sociedade brasileira recebeu uma carta de parabenização da relatora especial da Organização das Nações Unidas (ONU) para o Direito à Educação, Koumbou Boly Barry, pela manutenção de Paulo Freire como patrono da educação brasileira. No texto, Barry disse estar "muito feliz por saber que o lugar de Paulo Freire como patrono da educação brasileira permanece intacto, respeitando seu legado, memória e crenças". Em suas palavras: "a pedagogia de Paulo Freire representa o caminho mais seguro para a liberdade e para a promoção de uma sociedade justa e digna para todos" (Barry, 2018 apud RBD, 2018).

Considerando as manifestações de repúdio às ideias de Paulo Freire, presentes nos episódios descritos anteriormente, justificamos a importância deste estudo, que propõe, de um

\footnotetext{
${ }^{4}$ Para aprofundamento quanto às informações apresentadas indica-se a leitura da notícia completa disponível em: < http://agenciabrasil.ebc.com.br/politica/noticia/2017-12/senado-rejeita-proposta-de-retirar-de-paulo-freire$\underline{\text { titulo-de-patrono-da }}>$ Acesso em 25 de fev., 2018.
}

Revista Devir Educação, Lavras, vol.4, n.1, p.116-138 jan./jun., 2020. 
lado, a defesa sobre as contribuições de Paulo Freire nos processos formativos dos professores e, por outro lado, apresenta o que os professores de escolas públicas brasileiras, na atualidade, têm a dizer sobre o referencial teórico freireano como fonte de embasamento de suas concepções e ações pedagógicas. Assim, definimos como objetivo central deste estudo: identificar e analisar, no contexto atual, o que professores sabem sobre Paulo Freire, considerando a formação docente como importante espaço de (re)conhecimento sobre o autor.

A hipótese central deste estudo se refere à existência de lacunas nos cursos e/ou programas de formação inicial e continuada de professores quanto ao desenvolvimento de estudos da obra de Paulo Freire.

Partindo da problemática em torno do que os professores da atualidade sabem sobre Paulo Freire, utilizamos os resultados de um estudo desenvolvido a partir de depoimentos de vinte professores atuantes em escolas públicas de Educação Básica, localizas no município São José do Rio Preto/SP. Para a coleta dos depoimentos, utilizamos questionários, com questões abertas e fechadas, e realizamos entrevistas individuais semiestruturadas. Esse processo ocorreu entre os meses de setembro a novembro de 2016. Estamos obviamente conscientes do fato de que não é possível generalizar os resultados obtidos para a totalidade dos professores brasileiros, mas dadas as condições semelhantes de formação e vida profissional entre os professores entrevistados e a grande maioria dos professores brasileiros, acreditamos que os dados não seriam significativamente diferentes em outros municípios, mas só seria possível ter certeza disto a partir de novos estudos deste tipo em outras localidades.

A metodologia deste estudo fundamentou-se em uma perspectiva qualitativa pelas características e possibilidades desse tipo de abordagem e a relação com a nossa concepção de pesquisa científica, que, a saber, busca contribuir para o debate sobre as melhorias nos processos formativos dos professores e, sobretudo, na educação escolar a partir de uma análise minuciosa dos dados coletados. Por essa razão, os dados não foram apenas coletados e compartilhados e sim permeados de uma ação dialógica e reflexiva.

\section{A educação crítico-libertadora e os saberes docentes na obra de Paulo Freire}

O compromisso com a humanização do mundo é um dos princípios fundamentais no desenvolvimento da educação crítico-libertadora proposta por Freire (2003, 1987). Nessa perspectiva, o professor tem uma posição decisiva, por ser diretiva, de ajudar os alunos a serem

Revista Devir Educação, Lavras, vol.4, n.1, p.116-138 jan./jun., 2020. 
educados para a possibilidade de mudança. A mudança é alavanca da transformação social, e é um conceito posicionado ao lado do conceito de conscientização, segundo Freire (1979).

Ao assumir o papel de ser professor, ao decidir estar à frente da produção dos saberes escolares, o educador assume um compromisso com os alunos, com a comunidade escolar, com a sociedade. No entanto, esse compromisso pode se tornar uma palavra oca, uma abstração, se não for envolvida pela decisão lúcida e profunda de quem o assume, num processo de reflexão permanente e intencional.

Pautada no compromisso histórico, social e político, a postura do educador críticolibertador requer algumas características específicas à prática educativa. É o que Paulo Freire define como os saberes necessários à prática educativa. Trata-se dos saberes decorrentes da conduta profissional do professor diante da situação de ensino e aprendizagem. É a forma como o docente procederá na produção dos saberes dos alunos.

Sobre os saberes necessários à prática educativa, Freire (2002) faz uma profunda discussão, que é permeada pela reflexão acerca dos princípios da prática docente progressista. Entre esses princípios, destacam-se: autonomia, ética, liberdade, estímulo à curiosidade, dialogicidade, respeito aos educandos, competência, criticidade, rigor, coerência, compromisso, reflexão, humildade, alegria, amorosidade.

Freire (2002) ressalta a necessidade de identificação da prática docente progressista. Assim, por exemplo, Freire defende a necessidade da autoridade legítima, ao mesmo tempo que rejeita o autoritarismo. Não é rara a equivocada interpretação de certas posturas “dóceis" como educativo-progressistas, ao mesmo tempo, em que, por outro lado, é comum nos depararmos com práticas de ensino autoritárias, rígidas, mas que são consideradas eficazes na obtenção de resultados esperados pelos sistemas de ensino. Desta forma, é preciso ter clareza do que significa realmente uma prática educacional progressista.

A postura do professor progressista implica na recusa ou no rompimento das práticas autoritárias, verticalizadas, e das posturas de omissão (ou tentativa de imparcialidade) que ocultam as injustiças, mantendo a desumanização do mundo na contradição opressor/oprimido. Considerando a dimensão social da formação humana, Paulo Freire alerta para a postura permanente de reflexão crítica da e na realidade. O docente precisa compreender a forma como a sociedade é (ou está) organizada e ajude os alunos a fazerem essa captação crítica. Torna-se indispensável, no fazer docente, a reflexão e o diálogo sobre: o saber fazer, as causas da 


\section{Q0 DEVIR EDUCAÇÃO \\ ISSN: 2526-849X}

degradação humana, o discurso fatalista da desumanização, a força do discurso ideológico neoliberal, a lógica da "ética" de mercado, entre outros (Freire, 2002).

Essa prática - crítico-libertadora - é pautada nos princípios da solidariedade, da ética universal dos direitos humanos, na humanização, negando, portanto, às práticas arbitrárias e/ou ocultadoras da verdade. Quando o docente assume essa postura, de pensar e de se posicionar criticamente diante do mundo, pela humanização, está assumindo uma pedagogia da autonomia (Freire, 2002).

Para o autor,

Quando vivemos a autenticidade exigida pela prática de ensinar-aprender participamos de uma experiência total, diretiva, política, ideológica, gnosiológica, pedagógica, estética e ética, em que a boniteza deve achar-se de mãos dadas com a decência e com a serenidade. (Freire, 2002, p. 26).

Dos saberes necessários aos docentes, apresentados por Freire (2002), observamos a preocupação e o cuidado do autor na propositura de ações e de posturas voltadas a todas as áreas d a formação humana. Os princípios do inabacamento, a vocação ontológica do ser humano e a ética são retomados em toda a sua obra.

$\mathrm{O}(\mathrm{re})$ conhecimento quanto à vocação para evoluir e à opção pela postura ética lançanos a saber que:

[...] não há docência sem discência, as duas se explicam e seus sujeitos, apesar das diferenças que os conotam, não se reduzem à condição de objeto, um do outro. Quem ensina aprende ao ensinar e quem aprende ensina ao aprender (Freire, 2002, p. 25).

Outro saber presente em toda obra freireana se refere à indispensável postura reflexiva do professor sobre a relação teoria e prática. A ausência de reflexividade leva à alienação. A capacidade de reflexão crítica do professor deve ser incentivada nos alunos, incentivando-se concomitantemente a postura questionadora dos educandos (Freire, 2002).

É imprescindível que os docentes conheçam bem os conteúdos, os componentes curriculares, confrontando-os com a realidade, estabelecendo comparações e promovendo discussões com os alunos sobre o uso dos saberes ali produzidos na vida extraescolar. Esse movimento contribui para que a curiosidade espontânea seja, progressivamente, substituída 


\section{Q0 DEVIR EDUCAÇÃO \\ ISSN: 2526-849X}

pela curiosidade epistemológica. Nesse processo, a rigorisidade técnica é aliada ao conhecimento e repudia a licenciosidade e o espontaneísmo.

Outro saber fundamental apresentado por Freire (2002, p. 25) consiste em reconhecer e incorporar a ideia de que "ensinar não é transferir conhecimento, mas criar possibilidades para sua produção ou sua construção". Só é possível ao docente "pensar certo" se a sua prática docente for orientada por esse princípio.

O diálogo é mais que um saber, é um método para alcançar a educação democrática, no entanto, não basta o discurso, é preciso testemunhar o que se fala, ou seja, a fala só é legitimada por meio do exemplo concreto.

Um educador progressista não nega o compromisso social, histórico e político, mas, assume com responsabilidade as consequências dessa opção e exerce a sua prática com liberdade e autoridade. A segurança com que desempenha o seu papel é decisiva nessa posição.

Ao abordar os saberes necessários à prática educativa, Paulo Freire reitera o caráter humano da profissão docente, sem, no entanto, minimizar a importância do saber epistemológico. Segundo o autor, a discussão sobre os saberes fundamentais à prática progressista, que aqui chamamos de crítico-libertadora, deve ser conteúdo indispensável à formação docente (Freire, 2002).

Nessa luta pela consolidação de uma educação escolar democrática, o profissional do magistério é concebido por Freire (1997) como um profissional corajoso, que enfrenta todas as adversidades dessa profissão tão exigente. "Exigente de seriedade, de preparo científico, de preparo físico, emocional, afetivo. É uma tarefa que requer de quem com ela se compromete um gosto especial de querer bem não só aos outros, mas ao próprio processo que ela implica" (Freire 1997, p. 8).

Mas requer também autoconfiança, autoconhecimento, autovalorização e recusa contra as formas de desvalorização profissional. Portanto, é preciso elucidar que a que a tarefa de ensina não implica num "que-fazer de seres pacientes, dóceis, acomodados, porque portadores de missão tão exemplar que não pode se conciliar com atos de rebeldia, de protesto, como greves, por exemplo" (Freire, 1997, p. 9).

Freire $(1997,2002)$ discorre sobre uma série de qualidades necessárias ao professor progressista, que precisa equacionar a luta pela valorização da profissão e o amor pelo ofício de ensinar. Ressalta que é pela via da valorização que a profissão docente ficará mais “alegre”, 


\section{QO DEVIR EDUCAÇÃO}

ISSN: 2526-849X

mais leve, e poderá intervir de forma decisiva na mudança da escola pública. Não há expectativa de democratização educacional se o professor for submetido a condições de trabalho opressoras e desumanizantes.

\section{Os saberes dos professores e a sua formação profissional}

Na década de 1990, a partir das ideias de Donald Schön, emergiram muitos estudos em torno de um novo perfil profissional, referente àquele que se faz e/ou se desenvolve por meio da capacidade de refletir sobre as suas ações e concepções. Nesse mesmo período encontravamse em efervescência estudos sobre os saberes docentes, que buscavam a elucidação acerca de como os professores produzem os conhecimentos que orientam a sua prática. Assim, o saber epistemológico do professor e o desenvolvimento da práxis docente tornaram-se temáticas recorrentes em pesquisas científicas.

Entre as pesquisas ligadas aos saberes docentes, destacamos os estudos de Tardif (2012), em que realiza uma análise de como o professor produz os saberes validados por sua prática cotidiana. Para o autor, o saber docente é um saber do professor, um saber que ele produziu e continua produzindo baseado em suas relações passadas e do presente. Trata-se de um conjunto de saberes decorrentes da influência de vida pessoal, dos conhecimentos elaborados na trajetória escolar, dos conteúdos oriundos da formação profissional, dos componentes acadêmicos e curriculares transmitidos pelas instituições e, especialmente, da materialização dos saberes produzidos durante a atuação profissional. Os saberes docentes são efetivamente aquilo que está interiorizado no professor e que é traduzido pela sua prática.

Vale lembrar que as obras de Paulo Freire já traziam abordagens concernentes às questões mencionadas acima. Destaca-se que, ao denunciar a prática bancária de educação e propor uma educação libertadora, pautada na práxis dialógica, Freire $(1987,2002)$ revela que os saberes discentes e docentes são igualmente importantes no processo educativo. O caráter de inconclusão do ser humano e a sua vocação para o "ser mais" confirmam as abordagens relativas à natureza do saber plural de professores e de alunos.

Nas análises Tardif (2012) os saberes docentes são constitutivos dos saberes: da formação profissional, dos saberes disciplinares, dos saberes curriculares e dos saberes experienciais. Essas categorias auxiliam na compreensão quanto às dimensões dos saberes dos professores.

Revista Devir Educação, Lavras, vol.4, n.1, p.116-138 jan./jun., 2020. 
Em sua análise, o saber docente é constituído num contexto amplo, baseado em diferenciados saberes. Portanto, é "o saber plural, formado de diversos saberes provenientes das instituições de formação, da formação profissional, dos currículos e da prática cotidiana" (Tardif, 2012, p. 54).

Logo, o saber dos professores é a produção de conhecimentos, concepções, percepções, decorrentes de situações que influenciam o fazer da e na profissão professor. É um saber deles e está relacionado com a pessoa e a identidade deles, com as experiências de vida e com a história profissional, com as suas relações com os alunos em sala de aula e com os outros agentes escolares na escola (Tardif, 2012).

Consoante a isso, esclarecemos que, sem a pretensão de minimizar a pluralidade do saber docente, este estudo enfatiza a questão da influência da formação profissional na produção dos saberes dos professores. Especificamente, busca-se analisar a repercussão dos conhecimentos sobre Paulo Freire no campo da formação inicial e continuada de professores.

É importante elucidar que os saberes da formação profissional são caracterizados pelo conjunto de saberes transmitidos pelas instituições de formação de professores nos cursos e/ou programas de formação inicial ou continuada. Esses saberes são destinados à formação científica ou erudita e, se incorporados nas práticas docentes, podem ser transformados em práticas científicas. Nos saberes profissionais dos professores, há, ainda, os saberes pedagógicos, que são produzidos ao longo da formação. São concernentes às concepções oriundas de reflexões sobre as práticas, as técnicas e os métodos de ensino. São produzidos ao longo da formação (Tardif, 2012).

\section{Os saberes docentes na reflexão dos professores: resultados de uma pesquisa empírica}

Em concordância com Tardif (2012) quanto às influências da formação profissional na produção dos saberes docentes, buscamos abordar neste artigo a presença de Paulo Freire nas concepções pedagógicas dos docentes, tendo por base o referencial teórico produzido na formação inicial e continuada dos professores.

Sendo assim, apresentamos nesta seção os resultados de um estudo empírico, em que coletamos informações, junto a grupo de professores ${ }^{5}$, sobre a produção de seu referencial

\footnotetext{
${ }^{5}$ Para garantir o anonimato dos professores pesquisados e nos referirmos a eles, no lugar de seus nomes, utilizamos a letra P (professor/a) seguida de um numeral, indicando assim os vinte professores participantes. Exemplo: P1 ao
}

Revista Devir Educação, Lavras, vol.4, n.1, p.116-138 jan./jun., 2020. 


\section{QO DEVIR EDUCAÇÃO}

ISSN: 2526-849X

teórico e sobre suas concepções acerca de: a) a educação pública brasileira e b) a posição dos professores neste contexto. A coleta das informações foi feita por meio de questionários e de entrevistas individuais. Nas questões do questionário Paulo Freire não foi mencionado. Foram lançadas questões específicas sobre o referido autor na parte final das entrevistas.

$\mathrm{Na} 1^{\mathrm{a}}$ etapa da pesquisa, por meio de questionários, organizamos questões que nos possibilitaram verificar as concepções, os saberes docentes sobre os eixos temáticos centrais: 'concepção de escola' e 'concepção de professor'. Ainda nessa etapa, buscamos saber juntos aos docentes quais foram as 'principais fontes de produção dos saberes docentes'.

Sobre a 'concepção de escola' dos professores verificamos a presença de indicadores de um cenário conceitual conflituoso ou até mesmo indefinido. A partir dos relatos selecionamos os termos e/ou expressões-chave manifestados pelos professores, sendo eles: "crise", "não vai bem", "não é valorizada", "não acontece como deveria", "difícil definir", "elitista", "está perdida", "encontra muitas dificuldades", "falência na concepção", "ruim", "necessita de readequações", "sem norte", "um problema eminente", "falta muita coisa para melhorar", "muitos desafios", "desestruturada", "marginalizada".

De forma geral, observamos que os professores foram unânimes em denunciar que a instituição escola encontra-se num cenário marcado por crise, conflito e desesperança. Podemos notar, ainda nesses relatos, a falta de clareza nas definições. Não há concepções explicitas na descrição da escola, e há predominantemente indicações que "ela" não vai bem.

Buscando o aprofundamento quanto à 'concepção de escola' dos professores, lançamos uma questão mais específica, que trata sobre a função dessa instituição na atualidade. Nesse momento, verificamos que as respostas marcaram características ideológicas, possibilitando o agrupamento a partir categorias de análise, sendo elas: a) perspectiva progressista, b) perspectiva autoritária/assistencialista, c) perspectiva da alienação/lógica capitalista, d) falta de clareza na definição.

Apresentamos abaixo excertos de depoimentos dos professores quanto as suas concepções sobre a função da escola na atualidade. Esses relatos nos permitem verificar a organização temática descrita acima.

\section{a) Perspectiva progressista}

P20. Os depoimentos, marcando as falas dos professores, serão apresentados de forma semelhante a citações bibliográficas

Revista Devir Educação, Lavras, vol.4, n.1, p.116-138 jan./jun., 2020. 
$\mathrm{P} 1{ }^{6}$. A escola deve ser um espaço de desenvolvimento humano e aprendizagem.

P3. Proporcionar alguma possibilidade de mudança de vida para melhor através do estudo.

P5. É preciso ter no currículo conteúdos que preparem o aluno não somente para a vida profissional, mas também para saber viver e enfrentar a sociedade.

P8. A função central da escola pública é garantir um ensino de qualidade, permitindo a formação integral do aluno.

P11. Formar cidadãos capazes de atuar no mundo, conviver em sociedade, não apenas formar em relação aos conteúdos curriculares.

P14. A central está voltada para a formação de cidadãos conscientes, ou seja, na formação social das crianças e jovens.

P15. Garantir o acesso a uma educação de qualidade que vise à formação de sujeitos críticos, capazes de defenderem seus direitos e exercerem sua cidadania, conscientemente.

P16. A função central da escola deveria ser formar cidadãos críticos na sociedade, com seus direitos sendo realizados e seus deveres sendo cumpridos.

P17. Formar pessoas críticas, capazes de articular os conhecimentos historicamente acumulados e construídos no ambiente escolar com os diversos outros aspectos da vida humana. (QUESTIONÀRIO).

b) Perspectiva autoritária/assistencialista

P9. Hoje vejo a escola como um ambiente necessário para a sociedade para que se possa delegar os cuidados com o filho enquanto seus responsáveis trabalham ou têm outras atividades, assim como uma instituição em que se deve frequentar com a finalidade de certificação ao final de seu "percurso ideológico".

P10. Simplesmente tentar afastar as crianças, jovens e adolescentes da rua dizendo oferecer um ensino. Muitas escolas se transformaram em um depósito de pessoas. É obvio que é um direito da criança estar na escola, concordo plenamente com isso, mas estar em uma escola que ofereça qualidade principalmente no ensino.

P13. Dar acesso ao conhecimento formal.

\footnotetext{
${ }^{6}$ Os depoimentos, marcando as falas dos professores, serão apresentados de forma semelhante a citações bibliográficas.
} 


\section{Q0 DEVIR EDUCAÇÃO \\ ISSN: 2526-849X}

P18. Realizar a função que os familiares dos alunos não se comprometem. (QUESTIONÀRIO).

c) Perspectiva da alienação/lógica capitalista

P2. De um modo geral, a escola pública, hoje, serve para mascarar determinados dados do governo e manter o aluno como um analfabeto funcional.

P4. Acredito que seja garantir ao aluno conhecimento básico para o mercado de trabalho para atuar na sociedade.

P7. Formar uma mão de obra barata para o mercado e alienar de maneira sistemática os frequentadores do sistema público educacional. Me parece um desejo das elites, principalmente política, que permaneça assim.

P12. Preparar as crianças e jovens para se tornarem cidadãos e para o mundo do trabalho, dentro do atual estágio do capitalismo.

P20. Formar uma classe trabalhadora com baixa qualificação, apenas para cumprir regimentos legais no que tange à educação. (QUESTIONÁRIO).

d) Falta de clareza na definição

P6. Entendo que a função central da escola sempre será garantir ensino de qualidade para os alunos.

P19. Educar e não ensinar. (QUESTIONÀRIO).

Referente à perspectiva progressista de escola não é possível afirmar que os professores assumem essa concepção como orientação à prática docente, mas é possível identificar que em algum momento da produção de saberes houve acesso aos conhecimentos/conteúdos voltados à concepção de educação progressista.

Os docentes que demonstraram uma concepção de escola voltada à perspectiva autoritária/assistencialista, ao que parece, denunciam a perda da função da 'escola do passado', já que hoje, em suas opiniões, a escola tem que cumprir a função da família.

Os professores que declararam que a função da escola hoje é intencionalmente voltada aos interesses da lógica capitalista, demonstraram, se comparados aos demais, ter uma opinião crítico-reflexiva de maior complexidade e mais próximas das tensões políticas e sociais que vivemos historicamente e na atualidade.

Por fim, os professores que responderam de forma indefinida, ou genérica, 
demonstraram falta identidade e de reconhecimento de si e da escola no contexto atual. $\mathrm{O}$ que pode ser considerado uma situação de risco tanto no que se refere à postura assumida (talvez de omissão) como no tocante à influência sobre a formação de gerações de alunos que passaram e que passarão pelas suas mãos.

Vale esclarecer que, nesse eixo temático, não foi colocada em questão a opinião dos professores quanto a serem a favor ou contra a função cumprida pela escola hoje. Isso significa que não analisamos o que os professores idealizam, mas sim a crítica que fazem da realidade escolar da atualidade.

Referente às críticas/concepções dos professores quanto ao papel docente frente à escola da atualidade, lançamos ao grupo questões em torno do que pensam sobre essa questão e se acreditam que estão cumprindo esse papel. Nesse momento, foi possível notar características do pensamento freireano nos relatos de alguns professores, conforme os excertos abaixo.

Questões. a) Em sua concepção, qual é o papel do professor na escola pública brasileira? b) Você acredita que está cumprindo esse papel?

P5. a) Contribuir para a formação geral do aluno, não só na sistematização dos conteúdos, mas principalmente como cidadãos. Contribuir para a mudança do ser. b) Como eu gostaria não, porque isso depende de vários fatores. Por exemplo: condições de trabalho, condições de vida para os alunos. No que depende mim, sim, acho que cumpro o meu papel. Aqui neste bairro, a situação é muito difícil para os alunos. Alguns não vêm para a escola porque os pais não mandam. Aí eu vou até a casa deles, esse não é o meu papel, mas eu vou, e peço para as mães trazerem eles e percebo que com isso elas começam a enxergar a importância da escola para a vida deles. "Nada é impossível para aquele que persiste". Esse é o meu lema.

P7. Penso que seja: trabalhar a autoestima (emoções) dos alunos, propiciar o desenvolvimento de senso crítico e a aprendizagem da cultura humana necessária para a humanização do ser. b) Parcialmente, pois a realidade (muitas turmas, turmas numerosas, pouco tempo, programas extensos, cobranças inúteis, formações inadequadas...) dificulta o desenvolvimento do trabalho (Questionário).

Os depoimentos acima apresentam características da perspectiva freireana de educação ao demonstrarem compromisso histórico e social com os alunos e com a sociedade. Revelam o cuidado e a preocupação com o aluno, considerando-o como "ser humano" e não como a "clientela". Mostram reflexão crítica da realidade, prevalecendo a solidariedade social. É possível notar, ainda, entre outros aspectos, uma dose de autoavaliação dos dois professores, pois, ao serem questionados se estão cumprindo com o seu papel docente, a resposta não foi pronta, mas reflexiva.

Revista Devir Educação, Lavras, vol.4, n.1, p.116-138 jan./jun., 2020. 


\section{QO DEVIR EDUCAÇÃO}

ISSN: 2526-849X

Na sequência da coleta de dados sobre a mesma questão-tema, notamos outras três características, que se mostraram divergentes dos depoimentos acima. Um grupo manifestou respostas que visivelmente estão em conformidade com as expectativas presentes em documentos oficiais a serem seguidos pelos sistemas de ensino. Há relatos que carregam características da concepção bancária de educação e, por fim, há professores não apresentaram clareza nos depoimentos. A tabela abaixo mostra a frequência de professores conforme as características mencionadas acima.

Tabela 1 - Discursos dos professores quanto ao que pensam sobre o papel do professor.

\begin{tabular}{ccc}
\hline $\begin{array}{c}\text { 1. Discursos presentes em } \\
\text { documentos oficiais }\end{array}$ & $\begin{array}{c}\text { 2. Concepção bancária de } \\
\text { educação }\end{array}$ & $\begin{array}{c}\text { 3. Falta de clareza nas } \\
\text { respostas }\end{array}$ \\
\hline 12 professores & 4 professores & 2 professores \\
\hline $\begin{array}{c}\text { *Total de 18 } \\
\text { professores }\end{array}$ & & \\
\hline
\end{tabular}

Fonte: Elaborada pelos autores com base na pesquisa de campo.

* Os outros dois professores apresentaram discursos com marcas das ideias freireanas, conforme relatos apresentados anteriormente.

Referente aos itens 1, 2 e 3 da tabela acima, destacamos alguns termos e/ou expressões registradas pelos professores para expressarem o seu pensamento sobre a questão posta a eles, que se refere ao papel do professor na escola pública.

1. Mediar, formar, transformar, compartilhar conhecimento, promover um ensino de qualidade, formar cidadãos, preparar para o mundo do trabalho, desenvolver a formação integral do aluno, colaborar para a formação cidadã.

2. Ser autoritário, transmitir conhecimentos e exercer o mesmo papel que o professor da escola particular.

3. Agrega funções, um problema.

Os depoimentos representados pelas expressões acima mostraram a vulnerabilidade das concepções dos professores em torno de uma questão ligada diretamente ao desenvolvimento do fazer docente, o que nos leva a confirmar a crise identitária dos professores da atualidade.

Ainda na $1^{\mathrm{a}}$ etapa da pesquisa, por meio da realização de questionários, fizemos um levantamento sobre as principais fontes de produção dos saberes docentes identificadas pelo grupo pesquisado. A maioria dos professores indicou mais de uma fonte de produção de seus conhecimentos. A saber:

Revista Devir Educação, Lavras, vol.4, n.1, p.116-138 jan./jun., 2020. 


\section{QO DEVIR EDUCAÇÃO}

ISSN: 2526-849X

a) formação inicial: 11 professores

b) formação continuada fora da escola: 11 professores

c) formação em serviço dentro da escola: 4 professores

d) experiência prática: 7 professores

e) trocas de experiência com os pares: 3 professores

f) auto-formação (buscas pessoais): 8 professores

g) teóricos da área educacional: 4 professores

h) não especificou: 1 professor

As respostas evidenciaram que esses professores reconhecem a importância formação inicial e/ou continuada para os processos de produção de seus saberes. O que nos leva a refletir cada vez mais sobre as lacunas dos programas de formação no que tange às necessidades formativas dos docentes.

\section{O lugar de Paulo Freire nos saberes e na formação docente: a voz dos professores}

Prosseguindo na apresentação dos resultados desta pesquisa, no momento da abordagem sobre a presença teórica de Paulo Freire na formação inicial dos professores pesquisados, optamos por realizar uma entrevista individual, de modo que os docentes evidenciassem as suas respostas espontaneamente. Organizamos o desenvolvimento das entrevistas em dois momentos, um referente à $1^{\text {a }}$ etapa, em que Paulo Freire não foi mencionado e no segundo momento referente à $2^{\mathrm{a}}$ etapa da pesquisa, quando foram lançadas questões específicas sobre o autor.

Entre as questões lançadas na primeira parte da entrevista, solicitamos aos 20 professores que citassem os autores mais referenciados ou estudados em seu curso de licenciatura. Nas respostas, sete professores citaram espontaneamente Paulo Freire como referência teórica na graduação.

Entretanto, quando perguntamos objetivamente se tiveram estudos sobre Paulo Freire na graduação, obtivemos a seguinte frequência:

Tabela 2 - Estudos sobre a obra de Paulo Freire no curso de Licenciatura

\begin{tabular}{ccc}
\hline Sim & Não & Superficialmente \\
\hline P5 & P1 & P2 \\
P13 & P3 & P4 \\
P16 & P7 & P6 \\
P17 & P8 & P9
\end{tabular}

Revista Devir Educação, Lavras, vol.4, n.1, p.116-138 jan./jun., 2020. 


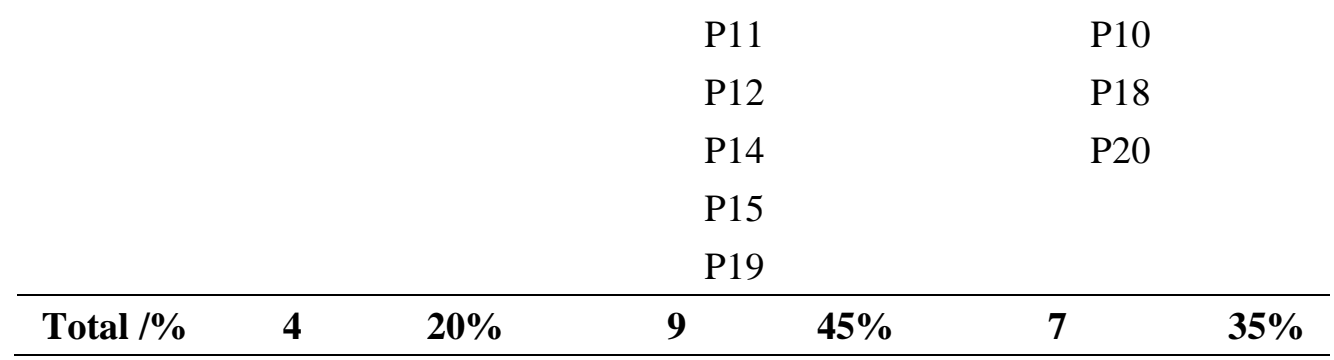

Fonte: Elaborado pelos autores com base na pesquisa de campo.

Os dados acima confirmam a hipótese inicial deste estudo quanto à lacuna nos cursos de formação inicial no que se refere à obra de Paulo Freire, pois apenas $20 \%$ dos entrevistados afirmaram que tiveram estudos que subsidiaram os conhecimentos sobre a teoria e a prática freireana. Ao passo que $45 \%$ do total pesquisado afirmaram que não tiveram estudos sobre o autor e os outros $35 \%$ declararam que tiveram acesso superficial à obra de Freire.

No tocante à formação continuada, fizemos a consulta junto aos professores, sobre os principais autores presentes nesse segmento formativo e obtivemos as seguintes respostas:

a) oito professores afirmaram que os referenciais teóricos/conteúdos abordados na formação continuada são selecionados pelos chefes imediatos ou por determinação do sistema de ensino em que atuam, sem que aja participação dos docentes nesse processo.

b) seis professores citaram autores específicos de sua área de atuação.

c) dois professores citaram Paulo Freire, e autores da área, como indicações de estudos na formação continuada na escola.

c) três professores não citaram nomes de autores.

d) um professor afirmou que estuda as obras de Paulo Freire, porém, a partir de buscas particulares.

Além da questão referente à ausência de Paulo Freire no repertório teórico no campo da formação continuada, outro dado que pode ser considerado alarmante nesse contexto de estudo consiste no alto número de professores que denunciaram a falta de participação docente nos processos de seleção de referenciais teóricos/conteúdos abordados em sua formação continuada. Cabe salientarmos que a questão posta solicitava somente informações a respeito de autores indicados para estudo neste segmento de formação docente. Não perguntamos sobre a forma como os autores ou conteúdos são selecionados. Esses dados confirmaram a falta de protagonismo do professor no desenvolvimento de políticas e de ações educacionais, fato que já vem sendo denunciado por alguns estudiosos, como Sacristán (2002), Giroux (1997), Roldão (2007). 


\section{Q0 DEVIR EDUCAÇÃO \\ ISSN: 2526-849X}

Seguindo nos resultados da pesquisa, após a questão sobre as referências bibliográficas dos cursos/programas de formação continuada, perguntamos aos docentes especificamente sobre a frequência de estudos da obra de Paulo Freire nos momentos de formação em serviço, em horários determinados pelo sistema de ensino em que atuam.

As respostas revelaram que $75 \%$ do total pesquisado, ou seja, 15 professores, afirmaram que não há estudos ou indicações de estudos sobre a obra de Paulo Freire e nem com base nela. Os demais docentes, $25 \%$ do grupo, afirmaram que há estudos superficiais da teoria freireana ou apenas utilização de citações que buscam relacionar as ideias do autor com determinados temas, o que, possivelmente, ocorre sem contextualizações da obra freireana.

Essas informações revelaram que os estudos da teoria e da prática de Paulo Freire não têm encontrado espaço para desenvolvimento na formação continuada de professores, especialmente nos processos formativos oferecidos pelo sistema de ensino ou pela escola.

\section{Afinal, o que os professores da atualidade sabem sobre Paulo Freire?}

Em entrevista individual, solicitamos aos professores pesquisados que falassem sobre Paulo Freire, expondo suas opiniões, pensamentos, lembranças, conhecimentos ou qualquer outra manifestação sobre o autor.

Pelos depoimentos, notamos que os docentes apresentaram respostas que se aproximavam entre si pelos seguintes eixos de análise: a) noção superficial a respeito da concepção de educação bancária; b) noção superficial a respeito do método de Paulo Freire; c) desconhecimento sobre a teoria do autor; d) visão política e social.

Para facilitar a compreensão do leitor quanto aos eixos referidos acima, selecionamos e destacamos a seguir alguns trechos dos depoimentos dos professores quanto as suas manifestações acerca de Paulo Freire.

a) Professores que demonstraram ter noção básica a respeito da concepção de educação bancária

P3. "[...] dar o protagonismo ao aluno, de fazer com que o aluno participe do processo todo para que ele não seja apenas um recebedor de conhecimento, mas que participe também, que ele consiga mostrar as suas habilidades [...]

P4. [...] uma educação em que o centro não é o professor, o centro é o aluno, uma educação voltada para o aluno [...] (ENTREVISTA).

Revista Devir Educação, Lavras, vol.4, n.1, p.116-138 jan./jun., 2020. 


\section{QO DEVIR EDUCAÇÃO \\ ISSN: 2526-849X}

Embora não tenham apresentado uma reflexão aprofundada sobre a obra de Paulo Freire, ao que tudo indica, os professores acima tiveram acesso a conteúdos da obra freireana em algum momento da formação, pois há coerência nas declarações no que se refere à crítica sobre a concepção bancária de educação.

b) Professores que demonstraram noção superficial a respeito do método de Paulo Freire

P9. [...] ele conseguiu alfabetizar em tempo recorde [... ] eu acho que eram 40 dias... o tema gerador que é do interesse do educando [...].

P11. [...] o que eu acho de interessante dele é a metodologia que ele criou para ensinar para os mais velhos [...].

P12. [...] ele tem ideias que são ainda muito à frente do que se propõe para os projetos de Educação do Brasil. O que a gente conhece bem do Paulo Freire é alfabetização de jovens e adultos. (ENTREVISTA).

Semelhante ao eixo anterior, os professores acima demonstraram saber algo sobre o método Paulo Freire, reconhecendo a importância do autor para o campo da alfabetização de adultos.

c) Professores que demonstraram desconhecimento sobre a teoria e prática do autor:

P2. Ele é pai da Educação, pai da pedagogia do amor.

P6. Acho que ele é importante. Fala do ambiente escolar.

P8. Não lembro... Tanto Paulo Freire como outros, nunca segui.

P10. [...] eu não me recordo certo para te falar [...].

P14. Sei que ele foi um grande estudioso, que tem bastante conteúdo dele que é ligado à educação.

P15. [...] a gente não tem referência dele. Até por ser... vamos dizer... até por uma coisa de ser um marco nosso... não tem nada específico, direcionado.

P16. [...] falam que ele é o pai da pedagogia [...] muitas coisas que ele falou são coisas básicas, mas que são necessárias serem ditas, porque... é igual, por exemplo, o Augusto Cury para educação de pais para filho (ENTREVISTA).

Os professores do eixo acima manifestaram desconhecimento sobre a teoria e a prática de Paulo Freire. Embora tenham ouvido falar do autor, alguns sabem que foi um estudioso, mas, 
não há elementos consistentes nos depoimentos que nos levem a outra análise que não seja a de desconhecimento da obra.

\section{d) Professores que demonstraram ter visão política e social pautada na}

obra freireana.

P1. [...] ele representa possibilidades para todos. Mostra que é possível mudar, é possível melhorar. Principalmente para os que vivem mais isolados, na periferia, como aqui neste bairro. [...] Paulo Freire é isso... é mostrar, principalmente para aquele que não tem perspectiva... mostrar possibilidades de mudar de vida, de sair dessa condição.

P5. Serve pra todos. [...] ele procura trabalhar com a parte crítica da formação do cidadão [...] existe o método, o método ele coloca, mas a forma como você coloca esse método tem que ser contextualizada de acordo com aquilo onde o ambiente, o meio que aquele cidadão vive.

P7. [...] é essa coisa da libertação, mesmo, conscientização [...] Entendi também que ele tinha essa prática libertária, de dar autonomia para esses oprimidos através da Educação. Não só através do caso de aprender, ter conhecimento, alfabetização, mas de ter consciência política, [...] ele é um libertário [...].

P13. [...] essa natureza social que ele consegue colocar de uma forma muito tranquila, eficiente dentro da Educação. [...] não consigo ver só como utopia utilizar no caso dentro da proposta dele a educação como meio de uma ascensão social. Não aquela coisa de que a educação é responsável por tudo [...] quando se propõe a tirar o indivíduo da ignorância, mas utilizando ali aquela realidade que teria algum sentido para eles e que conseguiria ter algum progresso [...].

P17. ...quando a gente pensa em Paulo Freire, a gente tem que pensar qual é o papel da educação pública. [...] Ele foi um homem corajoso, que enfrentou muitas e muitas batalhas para colocar as ideias dele, que eram revolucionários, em prática, e que até hoje enfrenta manifestações [...] eu acho que ele se inseriu num contexto político [...] é um tipo de leitura que te ajuda a ver a vida diferente, ver a escola de uma maneira diferente, ver a criança de uma maneira diferente [...].

P18. [...] as teorias que ele elaborou ao longo da vida dele... houve uma evolução de pensamento em relação à educação. [...] o aprendizado, a educação está nesse diálogo entre o professor e o aluno [...].

P19. [...] me chamou muito atenção a questão da ideia do Paulo Freire de que só dá para sair da condição social, mudar a sua condição social se você mudar primeiro a educação [...] Então, não dá para ter protagonismo se o educando ainda é oprimido, né? Oprimido de que forma? Oprimido nas ideias mesmo... a ideia de que para eu conseguir ascensão financeira, que é conforto material, viria através só do trabalho eu descobri que não, que tinha que vir através da educação e depois trabalho. Então, foi um autor libertador [...].

P20. Paulo Freire foi o primeiro brasileiro ou um dos únicos, na época, que já discutia o papel da educação como um papel libertador do trabalhador... A escola é o local em que o aluno vai refletir sobre esse problema. Hoje nós

Revista Devir Educação, Lavras, vol.4, n.1, p.116-138 jan./jun., 2020. 
estamos enfrentando a Escola Sem Partido, que é uma aberração, e Paulo Freire já falava disso lá no passado (ENTREVISTA).

Finalizando a pesquisa empírica, solicitamos aos professores que refletissem sobre os saberes que consideram necessários à prática educativa. Para explicitarem tais características, os termos mais frequentes verbalizados pelo grupo foram: "estudo", "conhecimento", “pesquisa”, “ética”, “amor”, “dedicação”, “disciplina”, "prática”, “empatia”, "experiência”.

Nesse momento, observamos que todos, inclusive os docentes que demonstraram desconhecimento sobre a teoria freireana, expressaram ou mencionaram princípios abordados por Paulo Freire como necessários à educação crítico-libertadora.

Esses resultados podem ser o indicador de que se de um lado os docentes apresentam predisposição à reflexão sobre as posturas e conhecimentos necessários à prática educativa sob a perspectiva freireana, do outro lado, cabe aos programas de formação docente organizarem as formas e os conteúdos programáticos que garantam esses estudos.

Considerando a influência e a importância do espaço de formação inicial e continuada de professores da educação básica, observamos que essas lacunas, referentes a estudos da teoria e prática de Paulo Freire, inviabilizam o desenvolvimento da educação escolar que defendemos: a educação crítico-libertadora.

\section{Considerações finais}

Este estudo busca contribuir para o debate sobre a necessidade de implementação dos cursos de formação inicial e continuada de professores, com o propósito de garantir que os docentes da atualidade conheçam e/ou aprofundem os seus conhecimentos sobre a obra de Paulo Freire.

Incorporar ou aprofundar estudos sobre a práxis freireana nos cursos e programas de formação continuada na escola nos parece o caminho viável para o desenvolvimento da educação para a mudança, para a substituição das ações antidemocráticas pela democracia social da escola.

Considerando a influência exercida pelos segmentos formativos, cremos que Paulo Freire pode ocupar um lugar de destaque nos referenciais teóricos dos professores, contribuindo na formação da identidade profissional e na formação de professores progressistas, mas isso 
requer o desenvolvimento de políticas estáveis e específicas de formação docente que valorizem essa visão libertadora de educação.

Por outo lado, tão importante se faz o desenvolvimento de ações dentro dos sistemas de ensino e das escolas públicas brasileiras no sentido de incorporarem a práxis freireana. $\mathrm{O}$ movimento dialógico de Paulo Freire favorece mudanças de paradigmas. Se a educação for desenvolvida nessa lógica, a comunidade escolar perceberá a autonomia da escola e começará a conceber essa educação como uma prática da democracia (Freire, 2003).

Defendemos que para Paulo Freire ocupar o espaço de referência teórica dos professores e contribuir efetivamente para o debate sobre a construção da escola pública crítico-libertadora, é fundamental a implementação de políticas e de ações específicas no âmbito da formação de professores. Isso significa tornar possível, por meio de ações concretas, os estudos efetivos sobre a obra do autor.

No caso da formação inicial, isso requer, no mínimo, o desenvolvimento de políticas referentes à reestruturação dos conteúdos programáticos e à forma como esses componentes são desenvolvidos nos cursos de licenciatura, de maneira que a prática bancária de formação seja substituída por práticas participativas e reflexivas dos futuros professores no desenvolvimento e/ou produção dos saberes docentes. É necessária a incorporação da obra de Paulo Freire nos referenciais teóricos de todos os cursos de licenciatura, afinal, a perspectiva do autor perpassa a profissão docente em sua totalidade, sem restrições de área e de segmento de ensino.

No âmbito da formação continuada, requer mudança na concepção de educação escolar por parte dos gestores educacionais da macro e da microesfera, o implica, entre outras coisas, a abertura da gestão educacional à construção coletiva dos conteúdos programáticos destinados à formação continuada de professores. Ainda nesse segmento, é necessária a implementação curricular dos programas e cursos de formação docente com a integração da obra de Paulo Freire nos referenciais teóricos, além do planejamento do tempo a ser destinado a estudos da obra freireana.

Entendemos, portanto, que a educação se caracterizará como prática da democracia quando a escola simultaneamente se abrir tanto às dimensões universais das potencialidades humanas quanto às condições e necessidades locais (Freire, 2003).

\section{Referências bibliográficas}

Revista Devir Educação, Lavras, vol.4, n.1, p.116-138 jan./jun., 2020. 


\section{Q0 DEVIR EDUCAÇÃO \\ ISSN: 2526-849X}

CORTELLA, Mário Sérgio. Paulo Freire: um pensamento clássico e atual. Revista ecurriculum, São Paulo, v. 7, n. 3, p. 1-14, dez. 2011. (Edição especial de aniversário de Paulo Freire). Disponível em: 〈http://revistas.pucsp.br/index.php/curriculum>. Acesso em: $10 \mathrm{fev}$. 2107.

CRAIDE, Sabrina. Senado rejeita proposta de retirar de Paulo Freire título de Patrono da Educação. Agência Brasil - Últimas notícias do Brasil e do mundo. Brasília, 2017. Disponível em: < http://agenciabrasil.ebc.com.br > Acesso em 22 de fev. 2018.

FREIRE, Paulo. Educação e Mudança. Rio de Janeiro: Paz e Terra, 1979.

FREIRE, Paulo. Pedagogia do Oprimido. 17. ed. Rio de Janeiro: Paz e Terra, 1987.

FREIRE, Paulo. Professora sim, tia não: cartas a quem ousa ensinar. São Paulo: Olha D’Água, 1997.

FREIRE, Paulo. Pedagogia da Autonomia: saberes necessários à prática educativa. 24. ed. São Paulo: Paz e Terra, 2002.

FREIRE, Paulo. Educação e Atualidade Brasileira. São Paulo: Cortez; Instituto Paulo Freire, 2003.

GIROUX, Henry. Os professores como intelectuais: rumo a uma pedagogia crítica da aprendizagem. Porto Alegre: Artes Médicas, 1997.

RBD, Redação. Relatora da ONU parabeniza Brasil por manter Paulo Freire patrono da educação. Rede Brasil Atual, 2018. Disponível em: <http://www.redebrasilatual.com.br/educacao/2018/02/relatora-da-onu-parabeniza-brasil-pormanter-paulo-freire-como-patrono-da-educacao > Acesso em 24 fev. 2018.

ROLDÃO, Maria do Céu. Função docente: natureza e construção do conhecimento profissional. Revista Brasileira de Educação, Rio de Janeiro, v. 12, n. 34, p. 94-103, jan./abr. 2007.

SACRISTÁN, José. Gimeno. Tendências investigativas na formação de professores. InterAção, Goiânia, v. 27, n. 2, p. 1-54, jul./dez. 2002.

STREIT, Maíra. Professor cria polêmica em protesto contra Paulo Freire: "Pedagogia do Oprimido é coitadismo". Revista Fórum, 19 mar. 2015. Disponível em: <http://www.revistaforum.com.br/2015/03/19/professor-cria-polemica-em-protesto-contrapaulo-freire-pedagogia-do-oprimido-e-coitadismo/> Acesso em: 25 jul. 2016.

TARDIF, Maurice. Saberes docentes e formação profissional. 14. ed. Petrópolis: Vozes, 2012.

Recebido em: 19/10/2019.

Aprovado em: 05/01/2020.

Revista Devir Educação, Lavras, vol.4, n.1, p.116-138 jan./jun., 2020. 